\title{
An exploratory study of early career teachers as culturally responsive teachers
}

\author{
Donna Tangen, Denise Ann Beutel, Rebecca Spooner-Lane \\ Queensland University of Technology, Australia.
}

\begin{abstract}
The purpose of this study was to advance understanding on how early career teachers imagined themselves to be culturally responsive and how their beliefs and ideologies about teaching a diverse range of learners were challenged and refined during their early years of teaching. This qualitative, exploratory study was conducted in a large, secondary school in eastern Australia that has a highly diverse population of students. Findings indicate that, while these early career teachers lacked preparation for working with diverse learners, building relationships on multiple levels (with students, with fellow beginning teachers, and with senior staff which includes ongoing support and mentoring from colleagues) is essential for the development of early career teachers as culturally responsive practitioners. Findings are discussed in relation to Garmon's (2005) six key factors for teaching diverse groups of students: openness, self-awareness, commitment to social justice, having intercultural experiences, have support group experiences, and recognising individual growth. These findings have implications for schooling systems in how they can better transition early career teachers to classrooms and for higher education teacher preparation programs in Australia and many other countries with a growing number migrant and refugee students coming into the school system.
\end{abstract}

Keywords: culturally responsive teaching; early career teachers; cultural diversity. 


\section{Introduction}

The diversity of the Australian population has broadened considerably over the past decade. According to the most recent census data (Australian Bureau of Statistics, 2017), approximately one third of people currently living in Australia were born overseas and approximately 21\% of the Australian population speak a language other than English at home. Over one half of this immigrant population reside in the state of Queensland, the context for this study. Along with this changing demographic, school classrooms have experienced a similar shift with a large increase in diversity in their student populations. Teachers are now required to be inclusive educators who cater for the ever increasing diverse needs of learners in their classrooms. However, there is evidence that some teachers have received little or inadequate training to work with diverse learners or may perceive that they do not have the capabilities to do so (Kaikkonen, 2010; Kraska \& Boyle, 2014; Rose, 2010). These teachers, as a consequence, see too many barriers to their engaging effectively with diverse learners which, in turn hinders their approach to working with diverse groups of students. Teachers with positive attitudes about inclusive education are more willing to accept diversity allowing students who may be marginalised greater opportunities to participate and gain membership in the class. While much literature in the area of teaching diversity has focused on the learning needs of students, the focus in this paper considers the perceptions of teachers who are working with culturally diverse learners. In particular we consider the perceptions early career teachers have of their themselves as culturally responsive teachers (Gay, 2010) through the various relationships they cultivate in their teaching practice. It is important to understand early career teachers' perspectives as they are at the beginning stages of their career, they are positioning themselves in their profession as culturally responsive practictioners.

\section{Culturally responsive teaching}

Being a culturally responsive teacher is a fundamental component of being an inclusive educator. According to Gay (2010) culturally responsive teaching involves teachers making use of students' cultural knowledge, prior learning, prior experiences and performance styles to make learning more relevant and effective. Teachers must be willing to adapt curriculum to be culturally relevant for their students, demonstrate and create a culture of caring for all students in their classroom, have some knowledge and/or experience of cross-cultural communication or be willing to develop these skills, and use culturally congruent instructional practices. The concept of culturally responsive teaching goes beyond employing ethnically tokenistic inclusive practices.

Siwatu (2011) and Bodur (2016) suggest that, if teachers are to develop as culturally responsive practitioners, then more explicit description of culturally responsive teaching 
needs to be embedded in teacher education programs. While completing coursework assignments provides preservice teachers with good background information for considering the process of teaching culturally diverse students, first-hand experiences provide a greater understanding of how the process is enacted. It is therefore proposed that preservice teachers need to be exposed to culturally diverse classrooms in their professional experience placements in schools throughout their teacher education programs. Garmon's (2005) research identified six key factors needed in preparing preservice teachers to become culturally responsive teachers. These key factors include openness (being receptive to others' ideas and to diversity), self-awareness (being self-reflective to gain insight and understanding of one's beliefs and attitudes about diversity and how these influence one's approach to teaching), commitment to social justice (involves the notion of equity and equality for all people in a society), having intercultural experiences (opportunities for direct contact with different cultural groups), having support group experiences (with peers, supervising teachers, lecturers, family, friends etc.) and encouraging an individual's growth in thinking more deeply about diversity, and educational experiences (in coursework and practicum) that contribute to changes in beliefs/attitudes about diversity. Building these six factors into teacher education supports the notion of building relationships on multiple levels as essential for effective teaching with diverse groups of students.

Teachers locate themselves in relation to the diversity of their students (Cummins, 2015). This self-positioning shapes not only their teacher practices but the interest and ability of their students to learn. While it is important to build relationships on multiple levels, it also needs to be acknowledged that in every classroom there is a power relationship that influences the teacher's role. One kind of power imbalance occurs when the teacher holds negative views about the non-dominant cultural groups of students in their class. When teachers create an environment of collaboration of power relationships by students having their identities affirmed, students are more likely to be positively engaged in learning. Hagenaur, Hascher and Volet (2015) found that student engagement is a significant predictor of teachers' emotional experiences in the class. Positive engagement creates feelings of joy about teaching while negative engagement results in teachers feeling anxious and angry. Teachers must recognise not only that their students have culturally legacies but that they too have cultural legacies that influence classroom interactions (Walter, 2018). Therefore, teachers must be aware of any personal cultural biases that they might bring into the classroom. Teachers' positive approaches to teaching can influence students and result in students experiencing positive emotions and feelings of well-being in relation to participating in class. The purpose of this qualitative study was to explore how early career teachers' beliefs and ideologies about teaching a diverse range of student learners were challenged and refined during their early years of teaching and to identify how early carrer teachers were supported in adapting to teaching culturally diverse students. 


\section{Method}

This qualitative study was conducted in a large school ( $\mathrm{n} \sim 2300$ students) in a low socioeconomic area of south-east Queensland, Australia. The school has a highly diverse population that includes students with Anglo-European backgrounds, students with backgrounds from the Pacific Islands (e.g. Samoa, Tonga), Maori students from New Zealand, students with Asian backgrounds (e.g. Chinese, Vietnamese) and approximately 8$10 \%$ of the students who identify as Indigenous Australians. Thirty-three percent (33\%) of students at the school speak English as an additional language or dialect (EALD). Each year, the school accepts large numbers of preservice teachers for practicum. Over the years, a significant number of these preservice teachers have been employed by the school as early career teachers. The research reported on in this paper was conducted with a group of these early career teachers.

Our overarching research question was: how are early career teachers' beliefs and ideologies about teaching a diverse range of student learners challenged and refined during their early years of teaching? Our research sub-question was: How are early career teachers supported in adapting to teaching culturally diverse students?

\subsection{Participants}

The participants in this study were six early career teachers at the school. Three of the teachers were in their first year of teaching and three were in the second year of teaching. All six teachers had completed a professional experience placement at the school prior to graduation and their subsequent employment. One teacher (female) was in the Special Education unit working with students with learning difficulties, one teacher was in a special English-as-an-additional language or dialect (EALD) unit, one teacher was a manual arts teacher; the other three teachers taught science and mathematics. All the teachers were born in Australia and were from Anglo-European backgrounds, which is fairly representative of teacher demographics in Australian schools.

\subsection{Data collection and analysis}

Ethical clearance and permission to conduct the study was received from the relevant university ethics committee and from the school. Data were collected via individual semistructured interviews with each of the six teachers at the school site. Interview questions included: What experiences prior to starting at the school did you have of working with divserity? How have your experiences at the school shaped your beliefs and understandings of diversity? And how are you supported in eaching to the diversity of students in your classrooms? Each interview was approximately 30-40 minutes long. The interviews were audiorecorded and pseudonyms were used in the transcriptions to maintain anonymity and confidentiality. The data were analysed deductively (Saldana, 2015) by the researchers using 
principles of thematic analysis. Garmon's (2005) six key factors for teaching culturally diverse learners: openness, self-awareness, commitment to social justice, having intercultural experiences, have support group experiences, and recognising individual growth were used as an analytic framework for examining early career teachers' developing selves as inclusive educators.

\section{Results and Discussion}

This research explored beginning teachers' developing teacher identity as culturally responsive educators. Findings indicated that building relationships on multiple levels (with students, with fellow beginning teachers, with senior staff and mentors) was essential for their development. In relation to Garmon's (2005) six key factors contributing to the development of culturally responsive teachers, all participants expressed an openness and a positive self-awareness in relation to teaching diverse learners and how their various, prior experiences helped to shape and influence their approaches to teaching diverse groups of learners.

Having been brought up in a diverse suburb and family, I have developed understanding of diversity through family (Participant 3, male, first-year teacher).

And from another

My own upbringing did not expose me to much diversity. However, I have done a lot of travelling, spent time in many countries and with people from many cultures and backgrounds. I enjoy learning things from and about different people and can see how different experiences shaped my view on things (Participant 2, female, second-year teaching).

Many of the participants described how they had purposely selected to do their final Professional Experience placement (practicum) at this particular school primarily to gain experience in working with diverse groups of learners. These proactive choices (Cummins, 2015) set the scene for a willingness of these teachers to learn how to develop positive teacher-student relationships which would, in turn, allow for a greater sense of empowerment for them and their students in the learning environment. The sentiment expressed in terms such as "be open and accepting”, "keeping an open mind" was conveyed by all the participants as the necessary foundation for their teaching.

Each of the participants described a strong commitment to social justice (Garmon, 2005) and worked with a focus to create learning opportunities that fit best with individuals in the groups of students they taught as well as for the whole class. They were encouraged by the '...small wins' and having '...realistic expectations' to keep students engaged over time toward gaining a larger sense of accomplishment. Developing positive relationships with students was the one way to realise these small wins. The teachers had some knowledge of 
and took consideration of their students' home lives in their personal relationships with them and in their curriculum planning. Differentiating the curriculum to fit the learning needs of students was described by each of the participants. While having a focus on the Australian curriculum that needed to be taught they adapted the curriculum to include students' cultural and individual needs. One participant, for example, described trying to embed Indigenous perspectives into the science curriculum which had the opposite effect than intended. Instead of being engaged students were disruptive in class. This student response perplexed the teacher as a requirement of the Australian curriculum and his teacher education indicated that he should embed Indigenous persepectives. Upon discussing the lack of student response with senior staff and his students, the teacher came to realise that while there were a few Indigenous students in his class, there were a greater number of students from other cultures, primarily South-sea Islander students whose culture he was not embedding in his lessons. This reflection and subsequent self-awareness (Garmon, 2005) on the part of the teacher led to him change his teaching approach to embed not only Indigenous perspectives but perspectives from the other cultures in his lessons with the outcome that students became more receptive and responsive to his teaching. This engagement, in turn, created a sense of well-being in this teacher that he was making positive connections with students and promoting their learning. This change in emotional engagement aligns with Hagenaur et al.'s (2015) suggestion that enjoyment is contagious in a classroom. If the students are happy with the process of learning, the teacher feels happy with the process of teaching. Adapting curriculum to fit in with students' culture is one way to give students a voice in the class. Through this voice they feel that their culture is acknowledged and respected. The participants saw themselves as significant partners in their learning.

Vital to the participants' sense of identity as culturally responsive teachers were the collegial relationships with other staff at the school. Being the junior staff members the participants felt well supported by colleagues. There were many professional development opportunities to learn about diversity, a mentor from senior staff was assigned to each of the participants, they were allowed time in their schedules to go into other classrooms and observe the strategies that other teachers used, and there were continuous conversations with fellow teachers about best practices for working with students. These beginning teachers were encouraged to believe that mistakes they made were learning opportunities and to take this idea as a reality and not simply an old adage that they had heard before. Being in an environment that took a whole-school approach to diversity and social justice participants described how they never felt a sense of isolation in their work nor that they had to work things out for themselves. There were a number of people they could call on to discuss problems that arose or to talk through what strategies might be the best to use with a certain group of students. This kind of support aligns with the notion of using 'roadmaps' as described by Oyserman et al. (2004) where the participants were striving to become the best teacher they could be, using the ideas and modelled behaviours of others but having the final 
say of what would work best for them in their own classroom. These positive examples and support created a high sense of agency in these beginning teachers which allowed them to feel comfortable in taking risks in trying new strategies in the classroom (Hagenaur et al., 2015).

In describing their journey to becoming culturally responsive teachers, the participants in our study described that they received little in their teacher education course that prepared them for working with diverse learners. As two participants described it:

There's not much that I've learnt through the contact time with the university that I've put in place...here, even the curriculum planning units that I thought would be really useful...but how we curriculum plan our units here is completely different (Participant 5, female, secondyear teacher).

What they described aligns with other research in the area (Miller \& Shifflet, 2016; FeimanNemser, 2001) that preservice teachers need real world contact and scenarios where they are encouraged to reflect more deeply on what it means to become a teacher and how to go about this. Without this connection to actual working scenarios preservice teachers must rely on their memories and ill-formed ideas of teaching. Preservice teachers need opportunities to understand what it means to be a culturally responsive teacher and how to enact being one. This is particularly important today in Australia and many other countries with the growing number migrant and refugee students coming into the school system.

\section{Conclusion}

The world continues to experience an increasing mobility of people from one country to another due to a range of global issues. Australia, like other countries has welcomed many migrants to come and settle into new lives. This study indicates that schools, like the one we describe, are transforming the way they approach teaching and learning. They have made the decision that all teachers need to understand how to work with a diverse range of learners and this is particularly important for their beginning teachers. These new recruits are starting off their teaching careers deeply embedded in a school ethos that celebrates diversity, not as a single day of recognition or with lip-service to the idea of diversity but with concrete, everyday hands-on teaching and learning. Immersion in such an environment can only result in these beginning teachers developing identities as culturally competent teachers. However, the study has highlighted that, in addition to better preparation in their preservice teacher education programs, teachers need ongoing support and mentoring from their teaching colleagues in their early years of teaching to best serve the needs of the diversity of learners in twenty first century classrooms. 


\section{References}

Australian Bureau of Statistics (2017). 2016 Census: Multicultural. Retrieved from http://www.abs.gov.au/ausstats/abs@.nsf/lookup/Media\%20Release3

Bodur, Y. (2016). Is cultural responsiveness part of effective teaching? Preservice teacher perspectives. Georgia Educational Researcher, 13(1), 112-133, DOI: 10.20429/ger.2016.130105

Cummins, J. (2015). Identities in motion: Rethinking teacher-student identity negotiation in multilingual school contexts. Australian Review of Applied Linguistics, 38(3), 99-105. DOI: 10.1075/aral383.01cum

Garmon, M. A. (2005). Six key factors for changing preservice teachers' attitudes/beliefs about diversity. Educational Studies, 38(3), 275-286, DOI: 10.1207/s15326993es3803

Gay, G. (2010). Acting on beliefs in teacher education for cultural diversity. Journal of Teacher Education, 61, 143-152, DOI: 10.1177/0022248109347320

Hagenaur, G., Hascher, T., \& Volet, S. E. (2015). Teacher emotions in the classroom: Associations with students' engagement, classroom discipline and the interpersonal teacher-student relationship. Journal of Psychological Education, 30,385-403 DOI: 10.1007/s10212-015-0250-0

Kaikkonen, L. (2010). Promoting teacher development for diversity. In R. Rose (Ed.), Confronting obstacles to Inclusion. International responses to developing inclusive education (pp. 171-183). NY: Routledge.

Kraska, J. \& Boyle, C. (2014). Attitudes of preschool and primary school pre-service teachers towards inclusive education. Asia-Pacific Journal of Teacher Education, 42(3), 228-246.

Rose, R. (Ed.) (2010). Confronting obstacles to inclusion: International responses to developing inclusive education. New York: Routledge.

Saldaña, J. (2015). The coding manual for qualitative researchers. Thousand Oaks, CA: Sage.

Siwatu, K. O. (2011). Preservice teachers' culturally responsive teaching self-efficacyforming experiences: a mixed methods study. The Journal of Educational Research, 104, 360-369, DOI: 10.1080/00220671.2010.487081

Walter, J. S. (2018). Global perspectives: making the shift from multiculturalism to culturally responsive teaching. General Music Today, 31(2), 24-28, DOI: $10.1177 / 1048371317720262$ 